\title{
COREOGRAFIA DE REDES DE INOVAÇÃO CONSTITUÍDAS A PARTIR DE UM LIVING LAB: UM ESTUDO DE CASO NA PLATAFORMA CORAIS
}

\section{COREOGRAPHY OF INNOVATION NETWORKS CONSTITUTED FROM A LAB LIVING: A CASE STUDY ON THE CORAL PLATFORM}

\section{Silvio Bitencourt da Silva, Dr. (UNISINOS)}

\section{Palavras Chave}

Rede; Inovação; Orquestração; Coreografia; Living Lab

\section{Key Words}

Network; Innovation; Orchestration; Choreography; Living Lab

\section{RESUMO}

O presente estudo investiga a ampliação dos papéis de coordenação e gerenciamento em redes de inovação aberta identificadas como Living Labs através de um modelo conceitual denominado de Coreografia. Trata-se de uma pesquisa qualitativa caracterizada como estudo de caso cuja unidade de análise se refere as ações tomadas para coordenação e gerenciamento da Plataforma Corais.org, já reconhecida como membro da European Network of Living Labs (Rede Europeia de Living Labs, em português). Os membros da rede participam de um processo de auto-organização em que a ordem emerge devido às interações entre membros em que simultaneamente todos estão envolvidos na gestão contínua da rede, onde a estrutura e o desempenho resultantes são co-produzidos por suas ações. Gera como implicações a teoria existente a criação de conhecimento sobre certas atividades auto-organizadas entre os membros da rede e orientadas pela informação: gestão do fluxo de conhecimento, gestão da apropriabilidade da inovação, gestão da estabilidade da rede e gestão da vitalidade e saúde da rede. Tais atividades levam à alavancagem da inovação e à coerência da inovação contribuindo com o alcance do resultado final de inovação de uma rede. Em termos gerenciais possibilita a obtenção de novos discernimentos quanto a liderança e o controle distribuídos entre os membros de redes de inovação em que os padrões de colaboração são mais relevantes na rede que os papéis individuais. As atividades inerentes a Coreografia possibilitam a definição de um tipo de modelo de gestão de relações colaborativas no uso de redes para o desenvolvimento de inovações.

\section{ABSTRACT}

The present study investigates the extension of coordination and management roles in open innovation networks identified as Living Labs through a conceptual model called Choreography. It is a qualitative research characterized as a case study whose unit of analysis refers to the actions taken to coordinate and manage the Corais.org Platform, already recognized as a member of the European Network of Living Labs ). Network members participate in a self-organizing process in which order emerges due to interactions between members where simultaneously everyone is involved in the ongoing management of the network where the resulting structure and performance are co-produced by their actions. It generates as implications the existing theory the creation of knowledge about certain self-organized activities between the members of the network and oriented by the information: management of the flow of knowledge, management of the appropriability of innovation, management of the stability of the network and management of the vitality and health of the network. Such activities lead to the leverage of innovation and the coherence of innovation contributing to the achievement of the final result of innovation of a network. In managerial terms, it makes it possible to obtain new insights about leadership and control distributed among members of innovation networks in which collaboration patterns are more relevant in the network than individual roles. The activities inherent to Choreography enable the definition of $a$ type of management model of collaborative relationships in the use of networks for the development of innovations. 


\section{INTRODUÇÃO}

Usualmente a gestão de uma rede de inovação é conduzida de acordo com o modelo de orquestração por uma liderança proeminente (hub), reconhecido como orquestrador.

Um dos exemplos de redes de inovação são Living Labs (DEKKERS, 2011). Promovidos inicialmente na Europa como um novo instrumento de política de inovação, constitui-se em um movimento que se manifesta em diferentes países a partir do apoio da European Network of Living Labs (Rede Europeia de Living Labs, em português). No Brasil emergiram a partir de 2009 com as primeiras adesões a ENoLL em sua 3a Onda com uma ênfase voltada a promoção de inovações sociais (SILVA, 2012; PINTO e FONSECA, 2013). No Brasil como um campo emergente de pesquisa tem gerado estudos relacionados ao tema que entre diferentes abordagens, procuram investigar como os living labs são geridos (SILVA, 2012; PINTO e FONSECA, 2013a; PINTO e FONSECA, 2013b; PINTO e FONSECA, 2013c; LITVIN et al., 2015; SILVA, 2015; e SILVA 2017).

Com base no papel desempenhado pelo hub podem ser identificadas duas formas diferentes de orquestração: uma integradora da inovação e a outra líder da plataforma de inovação (Nambisan; Sawhney, 2011).

Como integradora da inovação, o orquestrador define a arquitetura básica para a inovação e, em seguida, mobiliza os membros da rede, integra os diferentes recursos compartilhados para o desenvolvimento da inovação e conduz a sua destinação (Nambisan; Sawhney, 2011). Como líder da plataforma de inovação, o orquestrador define e oferece a arquitetura inovação básica, que então se torna a plataforma ou a base na qual outros membros da rede desenvolvem suas próprias inovações que podem ampliar e / ou melhorar a arquitetura base ou da plataforma (Nambisan; Sawhney, 2011).

De fato, como líder da plataforma de inovação é criado um contexto em que o poder decisório pode estar compartilhado entre todos os membros da rede. Assim, o modelo de orquestração passa a não ser mais adequado, pois não leva em conta todos os membros da rede de inovação constituída.

Tal constatação remete a seguinte questão de pesquisa: como são geridas redes de inovação constituídas a partir de um Living Lab orquestrado como uma Plataforma de Inovação? Neste sentido, este estudo pretende analisar a gestão de redes de inovação em que o poder decisório pode estar compartilhado entre todos os membros da rede constituídas a partir de um Living Lab orquestrado como uma Plataforma de Inovação. Neste artigo, superamos o modelo de orquestração a partir do hub (FERRARO; IOVANELLA, 2015; DHANARAJ; Parkhe, 2006; Ritala et al., 2009) em direção a um novo quadro organizacional denominado de coreografia (FERRARO; IOVANELLA, 2015), que leva em conta todos os membros da rede, ampliando os papéis de coordenação e gerenciamento em toda a rede.

Este artigo apresenta, além desta seção introdutória, mais quatro seções.: Seção 2: revisão bibliográfica sobre o tema; Seção 3: procedimentos metodológicos, onde são apresentados os métodos adotados para o desenvolvimento da pesquisa apresentada no artigo; seção 4: resultados. A seção final apresenta o referencial adotado.

\section{REVISÃO BIBLIOGRÁFICA SOBRE O TEMA}

\subsection{Da orquestração à coreografia}

A orquestração de rede de inovação pode ser definida como "o conjunto de ações deliberadas, intencionais realizada por uma empresa hub, uma vez que busca criar valor e extrair valor a partir da rede" (Dhanaraj; Parkhe , 2006, p. 659). "Tratam-se de atividades que permitem e facilitam (mas não ditam) a coordenação da rede para a realização dos resultados da inovação" (Ritala et al. 2012, p. 325).

A orquestração pode abranger diferentes processos de acordo com a concepção dos autores quanto a sua aplicabilidade. Este trabalho parte das três dimensões propostas de Dhanaraj e Parkhe (2006) e Ritala et al. (2009), que são a base para as outras variações mais específicas para a descrição da orquestração de redes de inovação.

De acordo com Dhanaraj e Parkhe (2006), e Ritala et al. (2009), existem três processos-chave para o exercício da orquestração de redes de inovação e que estão positivamente relacionados com a saída de inovação, que são: a) mobilidade do conhecimento, b) apropriabilidade da inovação, e) a estabilidade da rede. Esses processos são centrais para se compreender a orquestração de redes de inovação e são descritos a seguir.

O processo de mobilidade do conhecimento significa que recursos de conhecimento distribuídos na rede podem ser acessíveis aos seus membros. Refere-se ao compartilhamento, aquisição e implantação de conhecimento dentro da rede. O reforço a gestão da mobilidade do conhecimento inclui três tarefas específicas que orquestrador precisa manter a atenção: a absorção de conhecimento, a identificação de rede, e a socialização interorganizacional (Dhanaraj; Parkhe , 2006; Ritala et al. 2012).

O segundo processo chave é o de apropriabilidade da inovação que busca assegurar que os membros da rede 
são capazes de capturar os resultados gerados pelas inovações de forma equitativa que é, na verdade, assegurando a reciprocidade. A sua obtenção inclui as tarefas específicas que envolvem a promoção de confiança, de justiça processual, e posse de bens conjunta (Dhanaraj; Parkhe , 2006; Ritala et al. 2012).

O terceiro processo chave refere-se à estabilidade de rede que trata da disposição dos membros da rede em manter a colaboração entre si, o que está relacionado com o dinamismo de uma rede de inovação. Pode ser incrementada por meio de tarefas específicas voltadas para a melhoria da reputação, o aumento da sombra do futuro e a construção de multiplexidade (Dhanaraj; Parkhe , 2006; Ritala et al. 2012).

Entretanto, em algumas situações os papéis de coordenação da rede para a realização dos resultados da inovação podem ir além do modelo baseado no conjunto de ações de uma empresa hub ao levar em conta todos os membros da rede.

Tais atividades são realizadas através de instâncias de processos de orquestração alcançados pelo hub (Nambisan; Sawhney, 2011). O orquestrador, ou seja, o hub atua como controlador e executante e atua como líder na rede com a possibilidade de invocar a execução de processos de todos os membros.

Para estes casos, Ferraro e lovanella (2015) propõe a ideia de coreografia da rede de inovação que pode ser definida como a "capacidade da rede em promover colaboração entre múltiplos membros (FERRARO; IOVANELLA, 2015, p. 5). Dessa forma, não há um condutor, pois a coreografia abrange interações coordenadas entre duas ou mais partes que podem consistir em uma série de orquestrações.

Proveniente do grego, a palavra coreografia significa literalmente "a escrita da dança" (koreos = dança, movimento; grafia = escrita) e no contexto de redes de inovação reflete, segundo (FERRARO; IOVANELLA, 2015) alguns discernimentos da orquestração de redes de inovação (Dhanaraj; Parkhe , 2006), teoria da agência (STUDER et al., 2006) e Business Process Modeling - BPM (DECKER; WESKE, 2011)

As interações na coreografia segundo Ferraro e lovanella (2015) são instâncias concretas de atividades realizadas por membros que cumprem as regras e propósitos da rede. As atividades podem ser entre membros, por exemplo, em caso de fluxo de conhecimento quando dois ou mais agentes compartilham informações, ou podem estar dentro de agentes, onde tais atividades internas não são visíveis na rede.
Nas redes orquestradas, as atividades são implementadas de acordo com o papel dos membros na rede e limitadas pelos padrões correspondentes de composição da rede (FERRARO; IOVANELLA, 2015).

De fato, há um processo de auto-organização orientado por todos os membros da rede e suas interações em que a estrutura resultante (coreografia) e o desempenho é co-produzido por suas ações (WILKINSON; YOUNG, 1994; RITTER et al., 2004; FERRARO; IOVANELLA, 2015).

Na coreografia, segundo (FERRARO; IOVANELLA, 2015) a liderança é compartilhada e os diferentes membros são organizados sem uma hierarquia determinada, combinando espontaneamente seus recursos e capacidades para, assim como na orquestração, criar valor e extrair valor a partir da rede. Os benefícios são compartilhados entre os membros da rede de acordo com seus esforços. Na coreografia, "os recursos de rede e as melhores práticas são compartilhados e disseminados de forma ampla, em oposição a um modelo orquestrado, onde o hub tem controle total sobre seus membros" (FERRARO; IOVANELLA, 2015, p. 9).

Para Ferraro e lovanella (2015) a emergência da coreografia envolve a realização de certas atividades entre os membros da rede de inovação, que são: a) gestão do fluxo de conhecimento, b) gestão da apropriabilidade da inovação, c) gestão da estabilidade da rede e d) gestão da vitalidade e saúde da rede. Tais atividades são similares aos processos-chave requeridos de um hub na orquestração, mas com a diferença de que a coreografia é auto-organizada (FERRARO; IOVANELLA, 2015).

O fluxo de conhecimento, similar ao destacado na orquestração, consiste em trocar, compartilhar e usar informações entre membros da rede de inovação. No quadro proposto, a distribuição e combinação de conhecimento é permitida por uma ontologia que permite aos membros da rede de inovação conceitualizarem o que existe dentro da rede (FERRARO; IOVANELLA, 2015).

A apropriabilidade da inovação, assim como na orquestração, procura assegurar que os membros da rede de inovação são capazes de capturar os resultados gerados pelas inovações de forma equitativa. Na coreografia se permite uma distribuição equitativa de valor em função da diversidade dos membros e suas diferentes contribuições para a inovação (FERRARO; IOVANELLA, 2015).

Também, assim como na orquestração. a estabilidade aumenta a colaboração e reforça as relações entre os membros, reduzindo isolamento, movimentos de saída , perdas e comportamentos oportunistas (FERRARO IOVANELLA, 2015). 
Adicionalmente, a vitalidade e a saúde da rede se relacionam com a introdução de novos membros na rede, trazendo novos recursos, perspectivas e práticas inovadoras, bem como aos membros existentes que renovam suas contribuições para a rede (FERRARO; IOVANELLA, 2015).

Para os fins deste estudo, se busca compreender a gestão de redes de inovação em que o poder decisório pode estar compartilhado entre todos os membros da rede constituída a partir de um Living Lab orquestrado como uma Plataforma de Inovação. Para isso frente ao novo quadro organizacional denominado de coreografia (FERRARO; IOVANELLA, 2015).

Na próxima seção será apresentada e aprofundada a metodologia adotada neste estudo, bem como, os procedimentos de coleta e análise das evidências empíricas.

\section{MÉTODOS ADOTADOS PARA O DESENVOLVIMENTO DA PESQUISA APRESENTADA NO ARTIGO}

A investigação proposta sobre a ampliação dos papéis de coordenação e gerenciamento em redes de inovação aberta identificadas como Living Labs está pautada na compreensão das percepções e interpretações dos membros da rede. Remete, assim, a uma estratégia de pesquisa qualitativa, onde a opção pelo estudo de caso demonstra ser apropriada, para uma questão do tipo "como" ao permitir a preservação das características holísticas e significativas de eventos da vida real (YIN, 2014).

Os dados foram categorizados de acordo com o tratamento teórico realizado neste estudo, baseado principalmente em categorias de análise da pesquisa formadas a partir das atividades propostas pelo modelo de Coreografia: gestão do fluxo de conhecimento, gestão da apropriabilidade da inovação, gestão da estabilidade da rede e gestão da vitalidade e saúde da rede.

Para este estudo foi selecionada Plataforma Corais.org, um Living Lab já reconhecido como membro da European Network of Living Labs (Rede Européia de Living Labs, em português) que se configura como uma plataforma para desenvolvimento de projetos colaborativos.

A seleção levou em conta dois critérios: (1) o foco no desenvolvimento de inovações de modo colaborativo; (2) a regularidade de suas atividades em sua trajetória; e (3) manter ou ter mantido vínculo com a ENoLL.

As evidências vieram de três fontes distintas: documentos ou registros, entrevistas e acesso a diferentes mídias, incluindo a Plataforma Corais.org e alguns de seus desdobramentos.
Os documentos e registros complementares oriundos de eventos ou publicações sobre experiências do caso selecionado, contemplam o livro Design Livre e o Coralizando. O Design Livre é um livro colaborativo escrito em uma semana pela comunidade Faber-Ludens, publicado em PDF com projeto gráfico aberto e impresso sob demanda pelo Clube dos Autores em 2012. O Coralizando é um livro escrito colaborativamente, no ano de 2014, pela comunidade de usuários da Plataforma Corais sobre suas experiências e visões sobre a economia criativa e, além disso, permite compreender a utilidade das ferramentas colaborativas oferecidas por meio de histórias de como elas foram utilizadas em projetos específicos.

Buscou-se dar foco aos tópicos do estudo de caso em uma conversação guiada com base nos temas a serem explorados, porém dando oportunidades para que o entrevistado pudesse apresentar o que considera como aspectos mais relevantes em relação a uma determinada situação. Nesta direção, os entrevistados tiveram a possibilidade de expressar-se livremente sobre os tópicos propostos, assegurando que a entrevista tenha transcorrido de forma espontânea. Tal condição permitiu evitar uma possível reflexibilidade, ou seja, que o entrevistado entregasse ao entrevistador o que desejava ouvir.

Foram conduzidas quatro entrevistas por Skype com duração média de uma hora e registradas com equipamento de gravação de áudio com membros da rede e que integram a comunidade de usuários da Plataforma Corais.org baseadas em um roteiro semi-estruturado permitindo uma interação maior entre o entrevistado e o entrevistador.

O Quadro 1 apresenta a lista dos entrevistados no Living Lab pesquisado, suas funções, codificação para citações, e a duração de cada uma das entrevistas.

Quadro 1. Lista de entrevistados

\begin{tabular}{|l|l|l|l|}
\hline Living Lab & Código & Função & Duração \\
\hline Corais & E1 & $\begin{array}{l}\text { Responsável pela } \\
\text { Plataforma }\end{array}$ & $1: 34: 54$ \\
\hline Corais & E2 & Usuário líder A & $1: 01: 56$ \\
\hline Corais & E3 & Usuário líder B & $1: 12: 17$ \\
\hline Corais & E4 & Usuário líder C & $1: 07: 11$ \\
\hline
\end{tabular}

Fonte: Elaborado pelo autor. 
As entrevistas foram transcritas e os resultados obtidos a partir da realização da pesquisa empírica foram comparados com o padrão geral de resultados oriundo da literatura. Cada um dos relatos foi submetido para revisão pelos entrevistados de forma a se corroborar a sua integridade do relato. Não foram foram exigidas condições de anonimato ou confidencialidade.

Em relação as diferentes mídias, incluindo redes sociais, foram coletados dados e informações da ENoLL em seu endereço eletrônico <http://www.openlivinglabs. eu/>, e, particularmente em relação ao Living Lab pesquisado conforme segue: Corais.org: no endereço eletrônico do Living Lab <http://corais.org/>, além de alguns usos da Plataforma destacados no item de descrição do caso: principais projetos que estão ativos na plataforma.

\section{RESULTADOS}

A Plataforma Corais ou também chamada de (website) Corais < http://corais.org/> - é uma plataforma para o desenvolvimento de projetos em colaboração. Tal como um recife de corais oferece infraestrutura adequada para diferentes formas de vida marinha, o Corais oferta a arquitetura inovação básica com o objetivo de promover a proliferação de projetos em colaboração que contribuam para o bem comum. Os projetos são classificados em cinco tipos: projeto aberto e público, projeto moderado e público, projeto fechado e público, projeto privado e banco comunitário.

Cada projeto hospedado é considerado vivo enquanto houver colaboração das pessoas. Quando se torna inativo, as discussões e documentos gerados podem ser usados por novos projetos. Essa dinâmica de colaboração é análoga aos recifes de corais, que usam estruturas mortas como base para seu desenvolvimento.

Dessa forma, no Corais, tudo que é postado no sistema fica disponível para os participantes do projeto e também para qualquer pessoa que esteja logada. Cria, com essa condição, uma base de conhecimento pública para consultas em relação ao projeto em desenvolvimento ou como referência para outros que venham a ser desenvolvidos.

Além disso, pessoas fora do projeto podem interagir ou se juntar aos projetos existentes, não apenas limitando-se a consulta. A cada atualização no projeto os membros do grupo recebem uma notificação por e-mail, mantendo uma comunicação que assegura que todos são informados sobre o que está acontecendo.

Existem várias outras ferramentas similares no mercado, mas elas não promovem a formação de comunidades abertas e colaborativas como se propõem o Corais, pois por seu intermédio é possível conhecer novas pessoas e suas experiências. Além disso, como o código-fonte é livre, novas ferramentas são desenvolvidas constantemente pelos próprios usuários e/ou colaboradores dispostos a contribuir.

O Corais pode ser usado como uma rede social, colaborativa de fato, constituindo-se em um ambiente propício para o desenvolvimento de trabalhos coletivos, potencializando a criatividade através do estímulo a colaboração, além de incentivar a autonomia dos indivíduos na autogestão ou cogestão de projetos. A autogestão ou cogestão no Corais se refere a um modelo de gestão do trabalho colaborativo. Parte do princípio de que pessoas trabalhando juntas e alinhadas, com um senso de comum e responsabilidade, não necessitam de uma gestão centralizada. Nesta direção, todos participam da gestão ao mesmo tempo em que todos gerem a si próprios. $O$ entrevistado E1 reforça os argumentos sobrea a autogestão no contexto de atuação do Corais.

"Acho que uma das características importantes da auto-gestão são os lideres que não querem ser lideres. Eles não querem fazer o papel de chefe, que gerencia as tarefas para as demais.É uma pessoa que tem iniciativa, que tem presença. Ela vai cadastrar alguns conteúdos iniciais. Explicando para as pessoas que elas próprias vão cadastrando as tarefas, e verificando o que cada um está fazendo ou não. É uma cobrança horizontal. A característica da auto gestão. (E1)

O Corais permite, ainda, que projetos aconteçam mesmo que as pessoas envolvidas não possam se encontrar pessoalmente e mesmo que não haja recursos financeiros disponíveis. As tarefas podem ser geridas horizontalmente a partir das ferramentas disponibilizadas, sem que uma pessoa precise assumir a condução direta do projeto em desenvolvimento. Um das ferramentas, a moeda social, permite criar uma economia solidária entre os participantes de um projeto. Em síntese o Corais é feito para projetos que geram ou que fortalecem uma comunidade.

A Plataforma Corais é uma combinação de vários módulos de Drupal, um framework modular e um sistema de gerenciamento de conteúdo (CMS) escrito em (PHP) uma linguagem interpretada livre que permite criar e organizar conteúdo, manipular a aparência, automatizar tarefas administrativas e definir permissões e papéis para usuários e colaboradores. Na medida em que outros desenvolvedores se integram à equipe da Corais, é possível 
aprimorar a plataforma numa distribuição de Drupal própria, que permite criar e organizar conteúdo, manipular a aparência, automatizar tarefas administrativas e definir permissões e papéis para usuários e colaboradores. Por enquanto, está disponível apenas uma lista com todos os módulos utilizados e o código-fonte cru no GitHub, um Serviço de Web Hosting Compartilhado para projetos que usam o controle de versionamento Git, este um sistema de controle de versão (ou versionamento).

O Corais tem sua origem no Instituto Faber-Ludens de Design de Interação, uma entidade sem fins lucrativos que promove o desenvolvimento do Design e da Tecnologia no Brasil através da integração entre mercado e academia. Criou a Corais em 2011 para apoiar o desenvolvimento de qualquer classe de projetos abertos em outras organizações, sem necessariamente haver vínculos formais com o Instituto.

Em 2012, o Corais tornou-se independente do Instituto Faber-Ludens e, em 2013, mudou-se para o Instituto Ambiente em Movimento - IAM, uma associação sem fins lucrativos que visa a consciência ambiental da esfera individual à coletiva. No IAM, a plataforma é desenvolvida por Frederick van Amstel, com a participação aberta a qualquer usuário no projeto Metadesign, que visa o desenvolvimento da própria plataforma (ou seja, o próprio Corais é um projeto do Corais). Pauta-se em uma modalidade de design que antecede o projeto em si, na qual é possível construir instrumentos que ampliam as soluções possíveis em um determinado contexto. Esse momento é refletido pelo entrevistado E1.

"O Instituto Ambiente Movimento acolheu a Plataforma. Eu sou um voluntário do instituto, e desenvolvo a plataforma Corais como a principal atividade desse grupo. Não há um proprietário. Ela é um comum. Um espaço onde as pessoas cultivam e colhem em conjunto." (E1)

O Corais tornou-se um Living Lab filiado à Rede Europeia de Living Labs em 2012 por acreditar que é um espaço de desenvolvimento de projetos compartilhados por pessoas e organizações que desejam colaborar para inovar em conjunto. Sobre a adesão a ENoLL o entrevistado E1 observa que

"nós começamos o Corais como um projeto bem experimental, nós não sabíamos se ia vingar. Quando iniciou a terceira ou quarta onde, achamos que tinha relevância, nós termos o acesso dos conhecimentos em redes, que o ENoLL desenvolvia. Então agente se inscreveu, sem muita esperança ainda, visto que não temos um Living Lab tão tradicional." (E1)

Entretanto, em 2015 o Corais deixou de ser membro ativo da ENoLL em função de uma mudança de política de adesão que ocorreu no início de 2015 quanto ao pagamento de uma anuidade, a qual o Corais em sua condição atual de busca pela auto sustentação não permite arcar.

O Corais envolve laboratórios, salas de aula, comunidades e startups que acreditam no aprender fazendo, fazer aprendendo e, conta com diversos projetos públicos que integram membros de diversas regiões do Brasil. Sobre as características dos projetos, o entrevistado E1 reforça que

\begin{abstract}
"atualmente quem mais usa são produtores culturais. Mas no passado houve projetos de outras áreas. O projeto que mais teve relevância foi o de vocabulário da participação social, desenvolvido pela Cidade Democrática, visando permitir a participação dos cidadãos na cidade. Não tem nada a ver com o design, mas eles desenvolveriam esse projeto, que durou mais de um ano, 60 pessoas e quatro países." (E1)
\end{abstract}

Na sequência são descritas duas frentes de trabalho do Corais: a Plataforma como um projeto do Corais e suas publicações. Em relação a Plataforma são apresentadas as suas ferramentas, os principais projetos que estão ativos na plataforma e o ambiente de aprendizagem contínuo que se vale da Árvore do Conhecimento, incluindo um exemplo de seu uso que são os UX Cards e um exemplo de aprimoramento da Plataforma com a introdução da opção de moeda social a partir da participação dos usuários. A respeito das publicações além de diversos artigos e algumas dissertações, destacam-se os dois livros publicados. O Design Livre e o Coralizando. Todos são descritos a seguir.

\section{Ferramentas da Plataforma Corais}

O Corais oportuniza aos seus usuários diversas ferramentas de groupware, os softwares destinados ao trabaIho de grupos colaborativos que podem ser habilitadas nos ambientes dos projetos da plataforma, conforme observações dos entrevistados E1, E3 e E4 a seguir.

\footnotetext{
“O grande diferencial da Plataforma Corais é a grande variedade de ferramentas colaborativas integradas em um ambiente. Se você comparar com ferramentas comerciais, como o do Google,
} 
o GoogleDrive, o Corais tem mais ferramentas, todas e todos em um. Acho isso um grande diferencial do Corais, uma forma de integrar os documentos, até eu diria que desafia a maneira como as interfaces são organizadas. Por exemplo, não há pastas no Corais, fica muito fragmentado, ninguém saberia o que seriam esses documentos." (E1)

"Substitui o uso de softwares mainstream como p. ex. o Google Docs, etc." (E3)

"Por meio da Plataforma Corais temos a capacidade de organizar o trabalho e dividir tarefas" (E4)

No Corais qualquer pessoa pode criar um projeto colaborativo (Projeto aberto e público, Projeto moderado e público, Projeto fechado e público, Projeto privado e Banco Comunitário). A licença Creative Commons define como os conteúdos do projeto podem ser usados por outros projetos seja no Corais ou fora dele. Em essência, as licenças e instrumentos de direito de autor e de direitos conexos da Creative Commons estabelecem um equilíbrio no tradicional "todos os direitos reservados" criado pelas legislações de direito de autor e de direitos conexos. Os instrumentos Creative Commons fornecem a todos os criadores uma forma padronizada de atribuir autorizações de direito de autor e de direitos conexos aos seus trabalhos criativos.

\section{Principais projetos que estão ativos na Plataforma}

De acordo com a Plataforma, no período de conclusão deste estudo os Projetos que estavam "bombando" se referiam a Produtora Cultural Colabor@tiva.PE <http:// www.corais.org/colaborativape/dashboard>; a Comissão Nacional dos Pontos de Cultura <http://www.corais.org/ cnpdc/dashboard >; a Cooperativa de Trabalho Educação, Informação e Tecnologia para Autogestão (EITA) <http:// www.corais.org/eita>; o Sistema de Indicadores da Cidadania (Incid) <http://corais.org/incid>; a Rede de Observatórios <http://www.corais.org/observatorios>; e o GPACE <http://corais.org/gpace>.

A Produtora Cultural Colabor@tiva.PE é um arranjo produtivo local de pontos de cultura ligados à cultura digital e audiovisual de Pernambuco. Integram esta ação: CUCA Recife (www.nacaocultural.pe.gov.br/cucarecife), Canal Capibaribe (www.iteia.org.br/canalcapibaribe), Pontão iTEIA (www.iteia.org.br), Coco de Umbigada (www.nacaocultural.pe.gov.br/cocodeumbigada), Ponto de Cultura Tear Audiovisual (corais.org/tear), Ponto de Cultura Tecer (www.nacaocultural.org.br/tecer) e Ponto
Cinema de Animação Pernambuco (pontocinemadeanimacao.blogspot.com.br).

A Comissão Nacional dos Pontos de Cultura - CNPdC que atua no fortalecimento dos Pontos de Cultura em todo o território brasileiro. Trata-se de uma instância permanente de atuação e representação político-cultural, identificação de demandas e elaboração de propostas para o desenvolvimento de políticas públicas e de ações culturais no país. $\mathrm{O}$ grupo, que se articula através da Rede Nacional de Pontos de Cultura, é um movimento autônomo que cobra do Estado e, ao mesmo tempo, contribui com ele, abrindo canais de diálogo para avançar nas políticas públicas; com destaque para o Programa Cultura Viva, Mais Cultura e Sistema Nacional de Cultura.

A Cooperativa de Trabalho Educação, Informação e Tecnologia para Autogestão (EITA) possui como missão fortalecer as lutas de movimentos sociais do campo popular através da construção de tecnologias da informação livres e metodologias participativas para seu uso e apropriação.

O Sistema de Indicadores da Cidadania (Incid) é composto por indicadores que visam monitorar o estado da cidadania em 14 municípios do Leste Fluminense. O Incid é uma ferramenta para a garantia e ampliação dos direitos de cidadania que disponibiliza argumentos de interpelação, motivação e mobilização para

A implantação da "Rede de Observatórios" deu-se ao final do III Seminário Observatórios, Metodologias e Impactos nas Políticas Públicas: Estado, Sociedade, Democracia e Transparência com o objetivo de congregar os diferentes Observatórios como um espaço de intercâmbio de informações, aprendizagem e trabalho coletivo.

Os Observatórios têm se constituído através da análise crítica-construtiva, da informação, da formação e da pesquisa como um meio de colaborar para a transformação das práticas, das políticas e outros fatores envolvidos no desenvolvimento de distintas realidades sociais.

O GPACE é um grupo de pesquisa vinculado ao Programa de Pós-Graduação em Sociologia (PPGS) da Universidade Federal do Rio Grande do Sul (UFRGS) formado por pesquisadoras/es e estudantes interessadas/os na temática da ação coletiva, com o objetivo de construir uma agenda de investigação brasileira sobre processos organizativos e de mobilização social.

\section{Ambiente de aprendizagem contínuo}

Além dos projetos, existe um ambiente de aprendizagem contínuo, por meio da Árvore do Conhecimento na qual são armazenados conhecimentos disponíveis para execução de projetos, de forma colaborativa, 
como em um wiki, um tipo de software colaborativo que permite a edição coletiva de documentos usando um sistema que não necessita que o conteúdo seja revisto antes da sua publicação.

A construção colaborativa depende da maneira como os participantes do projeto usam as ferramentas disponíveis. Nos projetos a colaboração ocorre de maneiras distintas de acordo com a forma de trabalho dos usuários. Há os que preferem colaborar por meio de textos em tempo real, outros que preferem posts e comentários, outros que se concentram na distribuição de tarefas, e outros que trocam imagens e vídeos. Tudo depende da habilidade dos participantes em usar a ferramenta, pois a plataforma não impõe uma maneira específica para a colaboração.

Assim, no Corais é possível compartilhar o que sabe e aprender o que outros projetos compartilharam além de se criar uma tarefa em um projeto à partir de um conhecimento. O entrevistado E1 destaca a usabilidade da Árvore do Conhecimento.

“Na Árvore do Conhecimento, a pessoa pode manifestar o interesse por um conteúdo especifico e receber informações sobre este. Ou seja, se uma pessoa tem um dúvida todas as pessoas se manifestarem interesse por esse mesmo assunto recebem uma notificação por e-mail." (E1)

"A Plataforma é uma casca, as pessoas que dão o conteúdo. Nós não desenvolvemos os projetos." (E1) "A plataforma vai pega apenas ponta do iceberg que é informada. Esses outros pontos são discutidos em reuniões, e-mails, meios que não temos acessos. O que nós podemos fazer é apenas monitorar o que é comunidade na plataforma. É um monitoramento constante." (E1)

O Corais possibilita que todos possam contribuir e expandir o conhecimento da comunidade seja acrescentando ou corrigindo as informações disponíveis, bem como criar novos conhecimentos. O formato wiki permite o mapeamento, a auto e a cogestão das tradições coletivas, mesmo que um projeto se acabe. Ao utilizar um dos métodos da árvore em um projeto, é criado um link que adiciona o método como referência no projeto. Os usuários marcam entre as opções "estou estudando", "já estudei" ou "sou especialista".

Um exemplo de uso da árvore desenvolvido pela comunidade de design são os UX Cards, um baralho de cartões de conhecimento para projetar experiências do usuário (User experience -UX). Os cartões possuem validação prática e ficam visíveis nos perfis, compondo a identidade cognitiva de indivíduos e grupos, valorizando seus conhecimentos e o potencial para colaborar. Sendo público, os projetos na Plataforma Corais se tornam uma espécie de portfólio online para as pessoas participantes, expondo os trabalhos de forma rápida. O grande diferencial deste portfólio gerado pelo Corais é que todo o processo criativo de um projeto é exibido, criando uma base de exemplos para cada um dos métodos disponíveis na Árvore do Conhecimento, dando maior respaldo à pesquisa e concepções realizadas no decorrer do trabalho, onde tudo é documentado automaticamente.

\section{Exemplo de aprimoramento da Plataforma}

Como um exemplo de aprimoramento da Plataforma a partir do envolvimento dos usuários, é possível destacar a introdução da ferramenta de moeda social. Esta ferramenta permite uma economia solidária entre os participantes de um projeto. Assim, ao criar um projeto na Plataforma é possível selecionar um tipo de Banco Comunitário que traz habilitada a funcionalidade de moeda social e permite a associação de uma conta de usuário a um fundo comunitário. Ainda, na funcionalidade de moeda social é possível definir um símbolo e um ícone, bem como descrever sua origem e a relação comunitária. Cada moeda tem um valor máximo e um valor mínimo para cada usuário o que permite evitar acúmulo e concentração de capital e também o endividamento demasiado por parte de algum integrante do sistema financeiro. O entrevistado E2 destaca este aprimoramento da Plataforma.

“Esse trabalho aqui desenvolvido já existia an-
tes do Corais, nós trabalhávamos com planilhas,
com materiais gráficos, as atas ficam publicas
em um espaço interno, não na rede. Mas nós tí-
nhamos o desejo, mas não tínhamos um espaço.
Mas ao pesquisar softwares livres para a gestão,
me deparei com a ferramenta do Corais. Percebi
ali um potencial, apesar de ainda não ser bem
o que eu precisava, mas já tinha um grande ca-
minho percorrido. Como era um software livre,
com metadesign de desenvolvimento da ferra-
menta, eu me senti a vontade, integrante da-
quele projeto. Eu poderia ajustar a ferramenta,
era livre, poderia customizar. Eu tive a sorte de
que o principal desenvolvedor estava aberta a
novas ideias. Quando eu propus a ele um banco 
comunitário, que era algo que não tinha nada a ver com o Corais até então. Ele não gerencia bancos. Mas ao mesmo tempo, ele entendeu, mas comentou que não tinha conhecimento $s$ obre o dia a dia. Comentei, então, que nós tínhamos esse processo, mas não a ferramenta necessária para fazer online. Ele achou um modo grupal livre, que o permite uma moeda comunitária. Era exatamente o que nos estávamos modelando. Par ater essa confiança, era que fosse de conhecimento publico. Todas as informações são publicas, inclusive os não logados." (E2)

\section{Publicações}

No que se referem as publicações, há o livro Design Livre e o Coralizando, O Design Livre é um livro colaborativo escrito em uma semana pela comunidade FaberLudens, publicado em PDF com projeto gráfico aberto e impresso sob demanda pelo Clube dos Autores em 2012. Visa promover a proliferação de projetos livres e abertos, promovendo a inovação social. O Coralizando é um livro escrito colaborativamente, no ano de 2014, pela comunidade de usuários da Plataforma Corais sobre suas experiências e visões sobre a economia criativa e, além disso, permite compreender a utilidade das ferramentas colaborativas oferecidas por meio de histórias de como elas foram utilizadas em projetos específicos.

A seguir são descritas as evidências relacionadas a coreografia no Corais.

\section{Coreografia no Corais.org}

São descritas neste tópico as as atividades de coereografia na Patalaforma Corais.org.. Assim, apresentam-se a seguir as atividades entre os membros da rede de inovação, que são: a) gestão do fluxo de conhecimento, b) gestão da apropriabilidade da inovação, c) gestão da estabilidade da rede e d) gestão da vitalidade e saúde da rede (FERRARO; IOVANELLA, 2015)

A primeira atividade que se refere ao fluxo de conhecimento é conduzida no Corais por meio da troca, compartilhamento e uso da informação entre os membros da rede. Através da possibilidade de que os recursos de conhecimento distribuídos na rede podem ser acessíveis aos seus membros, o Corais, por meio de um corpo multidisciplinar composto por pessoas engajadas e dispostas a colaborar, apoiadas por tecnologias da informação e da comunicação permite que seja promovido o compartiIhamento e construção de conhecimento como um wiki em que se configura uma capacidade de aprendizagem que ultrapassa os limites da rede. Há um tipo de relacionamento vertical no âmbito dos projetos em desenvolvimento resultado do trabalho colaborativo a distância, favorecido pela construção coletiva do conhecimento e pela gestão compartilhada de projetos, e pelo provimento de uma série de ferramentas baseadas em software livre que ajudam as pessoas a se organizar com poucos recursos iniciais. Um outro tipo de relacionamento que ocorre horizontalmente que é oriundo do compartilhamento de conhecimento e informações entre projetos, além de manter a abertura a qualquer pessoa que queira buscar novos discernimentos a partir das experiências conduzidas na Plataforma. O entrevistado E1 destaca a amplitude do fluxo de conhecimento.

\begin{abstract}
"Nós monitoramos o número de visualizações da páginas, e esse número é muito superior ao número de membros, ou seja, existe uma utilização do conhecimento de maneira muito ampla. Como estatística, já passou de um milhão de visualizações." (E1)
\end{abstract}

A segunda trata da atividade de apropriabilidade da inovação que é conduzida no Corais por meio da distribuição equitativa de valor em função da diversidade dos membros e suas diferentes contribuições para a inovação. Há a promoção de sucessivas interações que são carregadas de ideais de reciprocidade, compartilhamento de conhecimento e resolução conjunta de problemas de acordo com a filosofia do Design Livre que permeia o Corais e que se expressa por meio das diferentes ferramentas de groupware que constituem a Plataforma ou, ainda no Metadesign ao se aprimorar a própria Plataforma.

A Plataforma Corais dispõe de ferramentas que possibilitam a efetivação dos canais de acompanhamento do coletivo, bem como participação nas tomadas de decisão. Blog, arquivo, tarefas, etapas, mapas mentais, planilha, calendário, são ferramentas úteis no que diz respeito ao acompanhamento do cotidiano do grupo. Já do ponto de vista da colaboração, as ferramentas votação, sugestão e texto colaborativo são as mais eficazes. $O$ trabalho colaborativo, tanto no âmbito do metadesign quanto no desenvolvimento dos projetos na Plataforma asseguram a abertura e transparência necessária para que os processos decisórios sejam tomados como justos, independente dos resultados. Como por exemplo, a aceitação ou não de ideias para implementação e novas funcionalidades na Plataforma. No caso da Moeda Digital, positivamente, criando um aprimoramento e, em discussão até o 
fechamento deste estudo a possibilidade de que o Corais também se torne uma rede federada. Em termos práticos, refere-se a possibilidade de se logar a partir de um perfil criado em uma mídia social federada e livre, ou, a partir de um perfil criado na Plataforma que demandaria a criação de um ambiente de "mídia social" e, a partir disso se conectar com usuários nas outras redes.

Quando alguém utiliza esta plataforma, está automaticamente contribuindo para a comunidade com conteúdo licenciado via Creative Commons que permite a cópia e compartilhamento com menos restrições que o tradicional "todos os direitos reservados". A próxima pessoa pode aprender com os projetos e, caso a licença permita obras derivadas, criar novos projetos baseados na ideia original. Projetos com direitos reservados não permitem esse tipo de interação. Se eles fossem permitidos, novos projetos iriam se valer da experiência dos projetos anteriores, sem, no entanto dar qualquer retorno à comunidade. O entrevistado E1 destaca sua percepção sobre o assunto.

“Com certeza, nós acompanhamos a publicação de tudo que sai na plataforma. Todo o novo projeto estamos olhando, o que está surgindo. Até agora não houve nenhum problema quanto a isso. Já foi utilizado por empresa privadas, isso também não é errado." (E1)

Entretanto, é demonstrada uma certa preocupação por parte do principal idealizador e responsável pelo Corais acerca das discussões feitas sobre o uso de algumas ferramentas ou acesso a informações criadas coletivamente para fins comerciais no intuito de assegurar a auto sustentação da Plataforma. Isso pode ser observado na observação do entrevistado E1.

"Ainda não sabemos. Essa é uma resposta que não posso te dar agora. Estamos bem preocupados com possíveis contradições que podem acontecer, pelo fato de estarmos explorando economicamente um produto que foi feito coletivamente." (E1)

A atividade voltada a promover a estabilidade da rede é conduzida de forma a assegurar a disposição dos seus membros em manter a colaboração entre si no desenvolvimento de projetos apropriando conhecimentos válidos. Tem sido alcançada por através da manutenção de sua filosofia de trabalho pautada no design livre, na qual se propõe quatro liberdades fundamentais, inspiradas nas liberdades do software livre: 1) a liberdade de aprender a usar, independente de um uso proposto ou esperado no projeto aberto que for consultado; 2) a liberdade de estudar e reproduzir o processo que gerou o produto através da consulta a documentação das decisões de design, os arquivos-fonte; 3 ) a liberdade de colaborar com o processo, inclusive alterando qualquer parte de um processo; e 4) a liberdade de aprender a fazer e, por consequência produzir e reproduzir. Dessa forma o nexo entre os movimentos atuais e futuras consequências é muito forte no Corais, pois no caso dos processos colaborativos, seja nas artes, na educação ou na tecnologia, construir um bem comum é a motivação principal que faz as pessoas colaborarem. De acordo com o entrevistado E3.

$$
\begin{aligned}
& \text { "Os usuários se envolvem na especificação e va- } \\
& \text { lidação e no uso com contribuições." (E3) }
\end{aligned}
$$

A vitalidade e a saúde da rede é criada de duas formas na Plataforma Corais. Uma delas refere-se aos Cartões UX que ao possuírem validação prática e ficarem visíveis nos perfis, compõem a identidade cognitiva de indivíduos e grupos, valorizando seus conhecimentos e o potencial para colaborar. A outra, em função do engajamento em torno de uma causa relevante em que os membros da rede buscam uma forma mais justa de fluir suas ações e ideias, partilhando valores e práticas em coletividades através de sua participação nos projetos que integram a plataforma. Através destas coletividades, por exemplo, a Plataforma Corais tem sido utilizada para organizar vários tipos de projetos: universidade livre, padronização de dados, reforma de prédio, produtoras culturais colaborativas, televisão inteligente, entre outros. Assim, as pessoas vão colaborando, ou como esta comunidade prefere dizer, vão "coralizando" ao criarem vínculos formais e informais decorrentes da sua participação em projetos e acesso e compartilhamento de informações com os outros existentes em um processo de socialização que atravessa as fronteiras própria rede. De acordo com o entrevistado E4.

\footnotetext{
"O uso do Corais propicia o trabalho em rede visando obter maior transparência e trabalho colaborativo como formas de propiciar o bem comum". (E4)

"Esta plataforma permite a criação de projetos autogestionados com a possibilidade de usar ferramentas das mais variadas, como textos colaborativos, votações, questionários, planilhas e
} 
arquivos. E transparente uma vez que todos os membros da comunidade podem visualizar todas as transferências entre colaboradores, assim como o estoque de Conchas de cada colaborador". (E4).

O Corais é constituído como uma rede apoiada em um ambiente virtual suportado por uma infraestrutura de funcionalidades expressas pelas ferramentas de groupware. Conduz suas operações como um Living Lab em dois níveis, sendo um o do projeto Metadesign, onde o Corais é um projeto da própria Plataforma e no nível dos projetos que "proliferam" no Corais, e o outro que se refere as possibilidades de colaboração tanto horizontal (entre projetos), quanto verticalmente (dentro dos projetos). Nele, os membros da rede participam de um processo de auto-organização em que a ordem emerge devido às interações entre membros em que simultaneamente todos estão envolvidos na gestão contínua da rede, onde a estrutura e o desempenho resultantes são co-produzidos por suas ações.

Este estudo gera como como implicações a teoria existente a criação de conhecimento sobre certas atividades auto-organizadas entre os membros da rede e orientadas pela informação: gestão do fluxo de conhecimento, gestão da apropriabilidade da inovação, gestão da estabilidade da rede e gestão da vitalidade e saúde da rede. Tais atividades levam à alavancagem da inovação e à coerência da inovação contribuindo com o alcance do resultado final de inovação de uma rede.

Em termos gerenciais possibilita a obtenção de novos discernimentos quanto a liderança e o controle distribuídos entre os membros de redes de inovação em que os padrões de colaboração são mais relevantes na rede que os papéis individuais. As atividades inerentes a Coreografia possibilitam a definição de um tipo de modelo de gestão de relações colaborativas no uso de redes para o desenvolvimento de inovações.

A principal limitação refere-se a dinâmica de transformações nos Living Labs brasileiros. Como se trata de um campo em desenvolvimento, especialmente no contexto empírico, ao longo da pesquisa, entre as investigações preliminares e a pesquisa propriamente dita, defrontou-se com projetos que cessaram suas atividades. Dessa maneira a pesquisa, limitou-se a um Living Lab de um total de doze que já estiveram em operação no Brasil considerados membros ativos da ENoLL e frente as características particulares do Corais como uma Plataforma de Inovação.
Futuras pesquisas neste campo de investigação podem emergir de novas incursões que buquem compreender em maior profundidade a coreografia, as atividades desevolvidas, além de estimular a condução de novas pesquisas que avaliem outros tipos de redes de inovação que permitam a obtenção de observações com maior poder de generalização. Entre os pontos de investigação a estrutura da rede de inovação e os resultados da inovação e sua caracterização, perspectivas não aprofundadas neste estudo.

\section{REFERÊNCIAS}

CORAIS. DISPONÍVEL EM: <HTTP://CORAIS.ORG/>, ACESSO EM 27/01/2017.

DECKER, G.; WESKE, M. Interaction-centric modeling of process choreography. Information Systems, No 36 , 292-312, 2011.

DEKKERS, R. Perspectives on Living Labs as innovation networks. International Journal of Networking \& Virtual Organisations, 8 (1), 58-85, 2011.

DHANARAJ, C.; PARKHE, A. Orchestrating innovation networks. Academy of Management Review, 31(3), 659-669, 2006.

DUTILLEUL, B.;BIRRER, F.A.J.;MENSINK, W.Unpacking European Living Labs: Analysing Innovation's Social Dimensions, Central European Journal of Public Policy, 4(June), 60-85, 2010.

FERRARO, G.; IOVANELLA, A. (2015). Organizing Collaboration in Inter-organizational Innovation Networks, from Orchestration to Choreography. International Journal of Engineering Business Management, Vol. 7, No 24, 1-14, 2015.

LEMINEN, S. Coordination and Participation in Living Lab Networks, Technology Innovation Management Review, November 5-14, 2013.

LEMINEN, S., NYSTRÖM, A., WESTERLUND, M. The effect $\mathbf{f}$ network structure on radical innovation in living labs. Journal of Business \& Industrial Marketing, 31, (6), 743757, 2016.

LEMINEN, S.; WESTERLUND, M.; NYSTRÖM, A. Living Labs as Open-Innovation Networks. Technology Innovation Management Review, September 6-11, 2012. 
LITVIN, A. K.; FRANZATO, C.; BORBA, G. et al. Os Living Labs como Plataforma de Metaprojeção, Sustentabilidade e Inovação Social. Mix Sustentável, v.1, n.2, 2015. 101-107 p..

NAMBISAN, S.; SAWHNEY, M. Orchestration processes in network-centric innovation: evidence from the field. The Academy of Management Perspectives, 25 (3), 4057, 2011.

NYSTRÖM, A. G.; LEMINEN, S., WESTERLUND, M.; KORTELAINEN, M. Actor roles and role patterns influencing innovation in living labs. Industrial Marketing Management, 43 (3), 483-495, 2014.

PINTO, M. De M. (org.) Desafios para a habitação de interesse social [recurso eletrônico]. Território do Bem / Míriam de Magdala Pinto (org.) - Dados eletrônicos. Vitória : EDUFES, 161 p. , 2017.

PINTO, M. De M. (org.) Redes de colaboração para inovação [recurso eletrônico]: a experiência do Living Lab Habitat / Míriam de Magdala Pinto (org.), Fabio Macal ... [et al.]. - Dados eletrônicos. - Vitória : EDUFES, 158 p. , 2014.

PINTO, M. De M.; FONSECA, L. P. Habitat Living Lab, red de innovación social y tecnológica. CTS - Revista Iberoamericana de Ciencia, Tecnología y Sociedad. 23 (8), 135-150, Mayo de 2013a.

PINTO, M. De M.; FONSECA, L. P. Profundizando la comprensión de los Living Labs de Brasil. CTS - Revista Iberoamericana de Ciencia, Tecnología y Sociedad. 23 (8), 231-247, Mayo de 2013b.

PINTO, M. De M.; FONSECA, L. P. Uso da análise de sistemas para aprofundar a compreensão das iniciativas de inovação aberta e centrada nos usuários. Strategic Design Research Journal, 6(3), 105-115, SeptemberDecember 2013c.

RITTER, T,; WILKINSON, I.F.; JOHNSTON, W.J. Managing in complex business networks.Industrial Marketing Management, Vol. 33, 175-183, 2004.

SILVA, S. B. A emergência dos Living Labs no Brasil como um meio para a promoção da Inovação Social. In: III Seminário de Ciências Sociais Aplicadas - Universidade do Extremo Sul Catarinense - UNESC, Vol. 3, No 3, 2012. Disponível em <http://periodicos.unesc.net/index.php/ seminariocsa/article/view/653>. Acesso em: 27/01/2017.

SILVA, S. B. Orquestrando Laboratórios Cidadãos: Um Estudo de Caso no TransLAB. Revista Interdisciplinar de Gestão Social - RIGS, Vol. 6, No 1, 101-122, janeiro-abril 2017.

SILVA, S. B. Um estudo exploratório sobre orquestração em Living Labs brasileiros. Revista Interdisciplinar de Gestão Social - RIGS, Vol. 4, No 2, 85-107, maio-agosto 2015.

STUDER, R., BENJAMINS, V. R., FENSEL, D. Knowledge Engineering: Principles and methods, Data \& Knowledge Engineering, No 25, 161-197, 2006.

WILKINSON, I. F.; YOUNG, L. C. Business Dancing The Nature and Role of Interfirm Relations in Business Strategy. Asia-Austrial Marketing Journal, Vol. 2, No 21, 6779, 1994.

YIN, R. P. Case Study Research: Design and Methods, Fifth Edition, SAGE Publications, Inc, 2014. 